\title{
Sanal dünyada gerçek eğitim fırsatları
}

\section{Real opportunities for education in the virtual world}

\author{
Mohamed Sukeik ${ }^{1}$, Fatih Küçükdurmaz²,3 \\ 1 Specialist Registrar, The Royal London Hospital, Whitechapel, London, E11BB, UK \\ ${ }^{2}$ Post Doc Research Fellow, Hip \& Knee Arthroplasty, The Rothman Institute at Thomas Jefferson University, \\ Department of Orthopaedic Research, Philadelphia, PA, USA \\ ${ }^{3}$ Bezmialem Vakıf Üniversitesi, Ortopedi ve Travmatoloji Anabilim Dalı, İstanbul
}

\begin{abstract}
Internette literatür veya benzeri mesleki bilgilere ulaşmak için arama yapmak pek çok doktor için günlük pratiğinin bir parçası haline gelmiştir. İnternetin doğası gereği arama sonuçlarındaki doğru ve kaliteli şekilde sunulmuş bilgiye ulaşmak son derece zaman kaybettirici hatta yıldırıcı olabilmektedir.

Daha etkin arama yapmak bazı arama tekniklerinin öğrenilmesi ile mümkün olabilir. Bir başka önemli konu da aramanın yapılabileceği farklı veya kısmen örtüşen veritabanlarını tarayan farklı arama motorlarının bilinmesidir. Bunların önde gelenleri Pubmed, Cochrane, EMBASE, Scopus ve Google Akademik'tir. Çoğu zaman kapsamlı bir arama yapmak için Pubmed, EMBASE ve Cochrane aramalarının birleştirilmesi gerekmektedir. Ayrıca, bu arama motorlarının bazıları tarafından hiç kapsanmayan ancak kapsamlı bir aramanın önemli bir unsuru olan ve "gri literatür" denilen başka bir veritabanı daha vardır.

Hekimlerin, özellikle de akademisyen olan veya olmayı hedefleyenlerin etkin ve kapsamlı bir arama yapabilmek için bütün bu konularda eğitim alması artık kaçınılmaz hale gelmiştir. Bu derlemede yukarıda bahsi geçen arama motorları ve bazı özellikleri hakkında genel bilgiler verilmektedir.
\end{abstract}

Anahtar sözcükler: internet; veritabanı; arama teknikleri; eğitim
Searching for literature or a professional knowledge became a part of routine daily practice for a majority of physicians. Accurate and high quality results may cost extended time consumption or even be deterrent due to the nature of internet.

Efficient search is possible only by learning and practicing some dedicated techniques. Beside this fact, it is important to be aware of the presence of various search engines working on different or partially overlapping databases. The most important search engines are Pubmed, Cochrane, EMBASE, Scopus and Google Scholar. Usually, a comprehensive result may require the combined search by seperate engines such as Pubmed, EMBASE and/or Cochrane. In addition, there is another database called "grey literature", excluded by some engines, which should be an important element of a comprehensive search.

It is inevitable for all physicians, but especially the ones who are or want to be a scholar in future, to be educated on these accurate and efficient search engines. In this review, a general information on the aforementioned, and some of their specifications and techniques.

Key words: internet; database; search engines; education nternetin bilimin her alanında olduğu gibi ortopedi ve travmatoloji alanında da devrim niteliğindeki etkileri oldu. İnternetin genel karakteri itibariyle bu etkilerini iletişim, paylaşım ve bilgi depolama imkânlarını arttırması şeklinde değerlendirebiliriz. Geleneksel yöntemleri iletişim ve eğitim yöntemlerinden başka imkânın olmadığı dönemlere şahit olan akademisyenler, son senelerde internetin eğitim ve iletişimde sağladığı kolaylıkları daha iyi fark edeceklerdir.

Geleneksel eğitim metotlarına göre internet, erişimi ve taşınması kolay, esnek, çeşitli formatlarda, ucuz ya da bedava ve kullanıcının kontrolünde olan platformlar sunmaktadır. Bu platformlar çeşitli teknolojik ürünlere uyumlu şekilde tasarlanmakta, bütün bunların yanında, kolayca da güncellenebilmektedir. Bütün bu nedenlerle, günümüzde web-tabanlı arama motorları, bibliyografik veritabanları (Google, Google Akademik, PubMed vb.), video paylaşım siteleri ve benzeri platformlar akademisyenlerin günlük hayatının bir parçası olmuştur.

Ancak, yapılan araştırmalar göstermektedir ki, doktorlar ve daha özelde ortopedi ve travmatoloji doktorlarının interneti etkin kullanma yöntemleri hakkındaki farkındalıkları düşüktür. ${ }^{[1]}$ Yukarıda bahsedildiği kadar

- Illetişim adresi: Assist. Prof. Dr. Fatih Küçükdurmaz, The Rothman Institute at Thomas Jefferson University, Department of Orthopaedic Research, Philadelphia, PA, USA Tel: +1(215) 8087320 e-posta: fatihmfk@hotmail.com

- Geliș tarihi: 24 Ekim $2014 \quad$ Kabul tarihi: 24 Ekim 2014 
geniş imkânlar sunan internetin içerisinde kaybolmadan hedefe yönelik aramalar yapmak, aslında eğitim gerektiren bir husustur. Aksi takdirde internet, son derece zaman kaybettirici ve hatta yanlış yönlendirici olabilir. ${ }^{[2]}$

Bu derlemede, sık kullanılan çevirimiçi veritabanlarının bazı temel özelliklerinden bahsedilecektir.

\section{VERITABANLARI VE ARAMA MOTORLARI}

Çevirimiçi veritabanları pek çok derginin indekslendiği ve buralardaki çalışmaların veya özetlerinin yer aldığı platformlardır ve bunlar genellikle haftalık olarak güncellenir.

\section{Pubmed}

En iyi bilinen ve ülkemizde de en sık kullanılan veritabanıdır. Amerikan Ulusal Kütüphanesi'ne (AUK) bağlı Biyoteknoloji Bilim Merkezi trafından geliştirilmiş ve işletilmektedir. Halihazırda yaklaşık 23 milyon atıf içermektedir. AUK'ye bağlı MEDLINE'ı içermektedir. Pubmed, her hafta Salı-Cumartesi günleri arasında güncellenir.

\section{Pubmed'i kişiselleştirmek}

Pubmed'in basit arama dişında da pek çok özelliği vardır. Bunlardan en önemlilerinden birisi kişisel- leştirilebilmesidir. Sitede yer alan "My NCBI" ikonu üzerinden ücretsiz hesap oluşturulabilmekte ve siteyi kullanmak ve bazı bilgileri depolamak mümkün olabilmektedir. Bu özellik üzerinden yaptığınız aramalar saklanabilir, ilgili konularla ilgili güncellemelerden otomatik uyarılar alınabilir, ilgi alanlariyla ilgili makale kolleksiyonları oluşturulabilir.

Ayrıca kişisel hesap oluşturmadan da son yapılan aramalara bakmak (recent history), seçilen makalelerin kullanılan bilgisayarda geçici olarak hafizada tutulma (clipboard), veya yazıma uygun formatta başka dosyalara aktarılma (File) fonksiyonlarını kullanmak mümkündür.

\section{MeSH ve Gelişmiş Arama (Advanced Search)}

Pubmed'de de aramalar anahtar kelimelerle yapılmaktadır. Bu nedenle kullanılan anahtar kelimeler tıbbi terimler hiyerarşisi altında düzenlenmiştir. Bu özellik sayesinde, sınıflama/arama yaparken daha hassas, gereksiz sonuçları eleyen bir hale getirilebilir.

MeSH'i kullanabilmek için önce arama yapılacak konudaki terimlerin belirlenip, terim hiyerarşisi (MeSH) içerinden seçilmeleri ve arama sorgusuna eklenmeleri gerekir (Şekil 1).

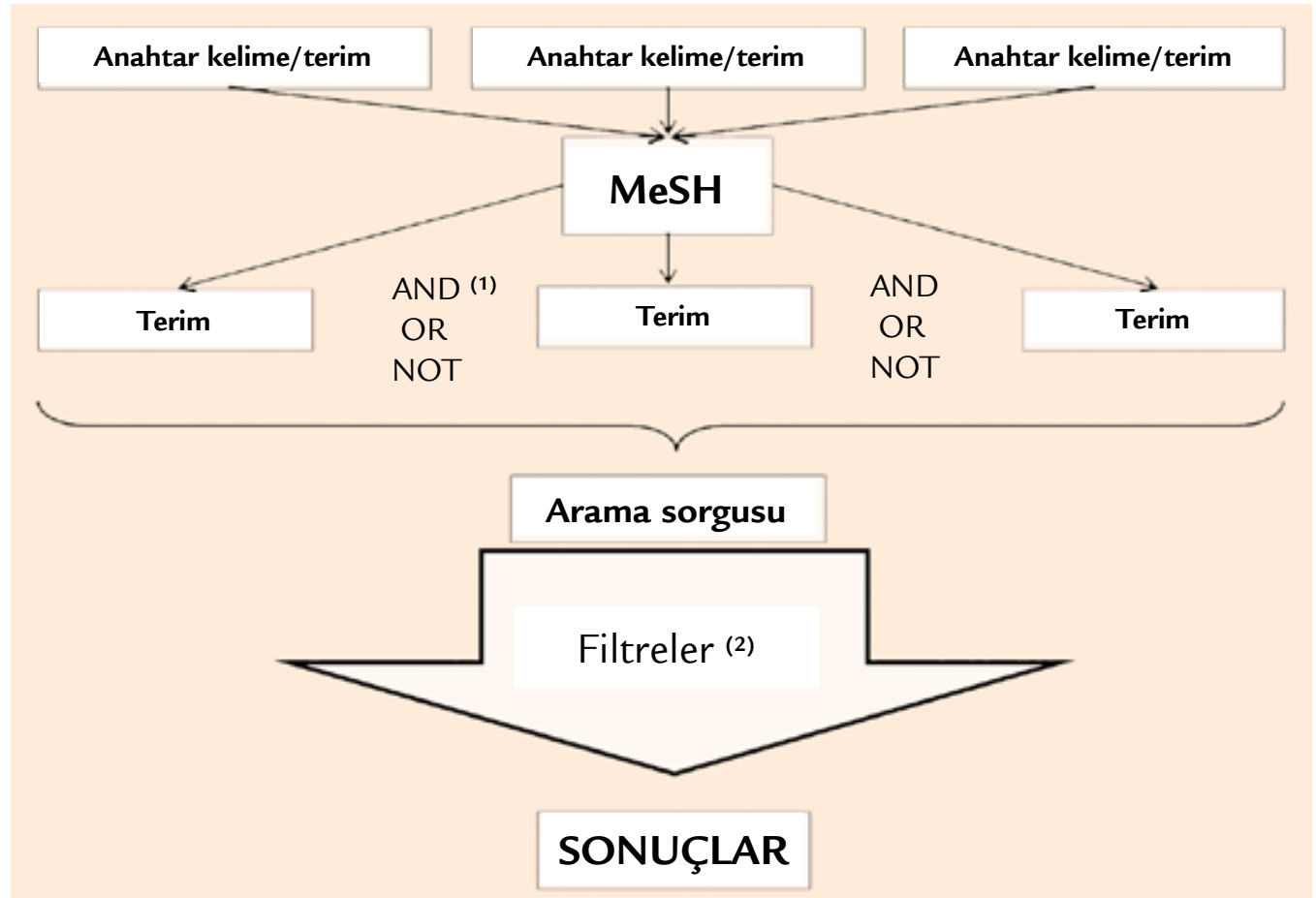

Şekil 1. Optimum bir literatür araması için $\mathrm{MeSH}$, terimleri birleştirme, ayırma ve hariç tutmakta kullanılan Boolean operatörleri (1), ve tarih, makale tipi, dil vs. (2) filtrelerinin kulanılması gerekir. 
Arama sorgusu oluşturulduktan sonra çeşitli filtreler kullanılarak, arama sonuçları daha rafine hale getirilebilir.

Gelişmiş arama özelliği sayesinde arama sonuçları birleştirilip, ayrıştırılabilir veya yazar, isim sırası, kurum, tarih, terimin makale içerisinde geçtiği yer gibi özelliklere göre ek filtrelemeler yapabilir. Bu gelişmiş özellikler, elle arama satırına yazılarak da yapılabilir (Tablo 1).

\section{EMBASE}

Excerpta Medica database (EMBASE) ülkemizde çok bilinmeyen ve kullanılmayan bir veritabanıdır ve kurumsal üyelik gerekmektedir. Elsevier tarafindan geliştirilmiştir. Yirmi beş milyondan fazla kayıt ve 7600'den fazla dergi içerir.[3] EMBASE, Avrupa'nın Pubmed'i olarak düşünülebilir. EMBASE ve Pubmed arasında \%40'a varan bir örtüşme söz konusudur. ${ }^{[4]}$ Pubmed'de olmayıp sadece EMBASE'de olan makaleler daha çok farmakoloji, psikiyatri ve biyomedikal mühendislik alanlarındadır. EMBASE, özellikle ilaç ve ilaç yan etkileri konularında son derece iyi bir indeksleme sistemine sahiptir.

\section{Cochrane}

Cochrane çevirimiçi kütüphanesi, altı alt veritabanı kolleksiyonundan oluşmaktadır. ${ }^{[5]}$ Bunlar:

- Cochrane Database of Systematic Review

- Cochrane Central Register of Controlled Trials (CENTRAL)

- Cochrane Methodology Register

- Database of Abstracts of Reviews of Effects (DARE)

- Health Technology Assessment Database

- NHS Economic Evaluation Database

- About the Cochrane Collaboration
Ocak 2014 itibariyle "Cochrane Database of Systematic Reviews" 6000 civarında derleme ve 2500 protokol içermekteydi. Kanıta dayalı tıp anlayışına göre hazırlanan ve metodolojik olarak yüksek kalitede çalışmalar içeren bir veritabanıdır. Cochrane sisteminin ücretsiz kullanımı ulusal düzeyde izin gerektirir. Bu sistem henüz Türkiye'de ücretsiz kullanıma açık değildir.

Cochrane sisteminde de Pubmed'de geçerli olan arama özelliklerinin çok benzerleri bulunur. Gelişmiş arama seçeneği aynen yer almakla birlikte arayüz uygulamaları farklılık gösterir.

\section{CINAHL}

Cumulative Index to Nursing and Allied Health Literature ifadesinin kısaltılması, CINAHL ile anılan bu arama motoru, hemşire ve hekimler dışında sağlık profesyonellerinin literatürünü içerir. Bu veritabanında 1300 derginin tam metnine ulaşılabilirken 4000 dergi de indekslenmektedir. Toplamda 1.000 .000 civarında kayıt bulunur. Ortopedi ve travmatoloji açısından metaanaliz çalışmalarında önem taşır. ${ }^{[6]}$ CINAHL, "EBSCO Publishing" tarafından oluşturulup yürütülmektedir. ${ }^{[7]}$

\section{Scopus}

Scopus kimya, fizik, matematik matematik ve mühendislik, sağlık bilimleri, sosyal bilimler, ekonomi, tarım, çevre bilimleri alanlarında multidisipliner bir veri tabanıdır. ${ }^{[8]}$ Pubmed'de yer alan pek çok makale Scopus'ta da indekslenmiştir.

Scopus bu özelliği ve kapsamıla Pubmed'den daha geniş bir arama yapmaya imkân verir. ${ }^{[9]}$ Pubmed'de indekslenen 23 milyon çalışmaya karşıık Scopus'ta 52 milyon kayıt mevcuttur. Ayrıca Scopus'ta yayınları atıf alma kriterine göre de aramak mümkündür. [10] Ayrica, Scopus toplantılarda ve konferanslarda

Tablo 1. Gelişmiş arama filtrelerini elle (manuel) kullanmak için gereken kısaltmalar

\begin{tabular}{ll}
\hline$[\mathrm{AU}]$ & Yazar \\
[author - first] veya [first author] veya [1AU] & Birinci yazar \\
[author - last] veya [last author] veya [LASTAU] & Son yazar \\
{$[$ journal] veya [TA] } & Dergi \\
{$[$ language] veya [LA] } & Dil \\
{$[$ PMID] } & Pubmed kimlik numarası \\
{$[$ publication type] veya [PT] } & Yayın tipi \\
{$[$ title] veya $[\mathrm{TI}]$} & Başlık \\
[title/abstract] veya [TIAB] & Başlık ve/veya özet \\
\hline
\end{tabular}

Bütün kısaltmalar, gösterildiği gibi köşeli parantez içerisinde kullanılmalıdır. 
sunulan özetleri de içermektedir. Bu avantajları aynında Scopus'un 1995'ten sonraki kayıtları içermesi ve kurum düzeyinde kayıt gerekliliği önemli iki dezavantajıdır.

\section{Google and Google Akademik}

Google hiç süphesiz sadece tıp alanında değil, her alan ve konuda arama motorlarının lideri durumundadır. Sağlıkla ilgili bilgi aramanın sadece doktorlar değil hastalar tarafından da en sık yapıldığı arama motorudur. Üstelik bu durum İngilizce dışındaki diller için de aynıdır. ${ }^{[11]}$ Ancak bu kadar geniş bir veritabanına sahip olmak, rafine ve odaklı bir arama yapmayı zorlaştıran bir durumdur.

Google, akademisyenlere yönelik olarak Kasım 2004'te Google Akademik (Google Scholar) adlı bir uygulama geliştirdi. Google Akademik, yüzeysel ve hızlı bir arama yapmak için elverişli olmakla birlikte daha derinlemesine ve odaklı bir arama yapmak için yukarıda adı geçen arama motorlarına ihtiyaç vardır. ${ }^{[12]}$

\section{Google Akademik'te indekslenen çalışmalar}

- Akademik makaleler

- Makale basım öncesi kopyalar

- Tezler

- Teknik raporlar

- Akademik kitaplar

- Makale özetleri

- Patentler

\section{Google Akademik'te indekslenmeyen çalışmalar}

- Haberler

- Akademik olmayan dergilerin makaleleri

- Basın açıklamaları

- Fotoğraflar

- Kitap değerlendirmeleri

Shariff ve arkadaşları, PubMed ve Google Akademik'i karşılaştırmış, Google Akademik'in iki kat fazla makale bulduğunu (PubMed, 11\%; Google Scholar, 22\%. $P<0,001)$ ortaya koymuştur. Aynı şekilde, Google Akademik ile daha fazla sayıda ücretsiz makaleye (PubMed, 5\%; Google Scholar, 14\%. $P<$ $0,001)$ ulaşmak mümkün olabilmiştir.[13] Benzer sonuçlar Nourbakhsh ve arkadaşları tarafindan da bulunmuş, Google Akademik yoluyla ulaşılan makalelerin daha yüksek etki faktörü (impact factor) olan ve daha fazla atıf yapılan makaleler olduğu ifade edilmiştir. ${ }^{[14]}$ Google arama motorunda çalışan bazı operatörler aşağıdaki gibidir: "site:" operatöründen sonra yazılacak uzantıların olduğu sayfalarda arama yapar (edu, com, org vs.)

“filetype:" operatöründen sonra yazılacak uzantıların tipindeki formatta dosyaları arar (ppt, doc, pdf vs.).

“OR” operatöründen önceki veya sonraki terimi içeren siteleri arar.

“AND” operatörünün öncesindeki ve sonrasındaki terimi beraber içeren siteleri arar.

“NOT” operatöründen önceki anahtar kelimeyi içerip veya sonrakini içermeyen siteleri arar.

\section{GRI LITERATÜR}

Gri literatür, ticari amaçlı basım şirketleri (Elsevier, Springer vs.) tarafindan kontrol edilmeyen basılı ya da elektronik formattaki akademik çalışmaların oluşturduğu literatür olarak tanımlanır. ${ }^{[15]}$ Bu literatür, kitap ya da dergilerde basılmamış çalışmaları içerir. ${ }^{[16]} \mathrm{Bu}$, özellikle yayın haline getirilmemiş çalışmaları, toplantı sunumlarını içermesi açısından önemlidir. Cochrane derlemelerindeki kaynakların \%10'unun toplantı sunumlarından oluşması, gri literatürün kanıta dayalı tıp açısından önemli olabileceğini ortaya koymaktadır. ${ }^{[17]}$

Gri literatür hakkında yapılmış çalışmalar, bu literatürün bazı farklıııklar taşıdığını göstermiştir. ${ }^{[18]}$

Gri literatür, genellikle çalışmalarda yer alan gruplar arasında belirgin fark bulunmamış sonuçları içeren çalışmalardır. Bu tip sonuçları olan çalışmalar, yapanlar tarafından daha az basılma eğilimindedir ve bu aslında bir taraf tutmadır. ${ }^{19-21]}$ Ayrıca, sonuçlarında gruplar arasında belirgin farklılık bulunan çalışmalar, Ingilizce olarak global erişimi mümkün olan ve nispeten daha yüksek etki faktörü olan dergilerde basılma eğilimindedir. ${ }^{[22]}$ Bu yönüyle, gri literatürün bilimsel çalışmalar yaparken kaynaklar arasında taramaya katılması, kanıta dayalı sonuçlar elde etmek açısından çok önemlidir.

\section{SONUÇLAR}

Akademisyenler ve kariyerinin her aşamasındaki araştırmacıların interneti mesleki amaçlarla kullanırken, zaman kazandıran, daha doğru sonuçlara ulaştıran, kapsayıcı, güncel ve odaklanmış aramalar yapabilmeleri çok önemlidir. Ancak bunu yapabilmeleri için arama yapma konusunda eğitim almaları gerekir. Yurtdışında, akademisyenlerin eğitiminin resmi bir kısmı olan bu konuya ülkemizde de hak ettiği önem verilmelidir. Halihazırda ülkemizdeki araştırmacılara, yine internetten ulaşabilecekleri görsel ve yazılı literatür tarama teknikleriyle ilgili dokümanları incelemelerini tavsiye ederiz. 


\section{KAYNAKLAR}

1. Sinkov VA, Andres BM, Wheeless CR, Frassica FJ. Internetbased learning. Clin Orthop Relat Res 2004;(421):99-106.

2. Falagas ME, Ntziora F, Makris GC, Malietzis GA, Rafailidis PI. Do PubMed and Google searches help medical students and young doctors reach the correct diagnosis? A pilot study. Eur J Intern Med 2009;20(8):788-90. CrossRef

3. Elsevier Life Science Solutions. Embase; 2014. http://www. elsevier.com/online-tools/embase/about

4. Barratt $\mathrm{H}$. Electronic bibliographical databases and their limitations. HealthKnowledge; 2009. http:// www.healthknowledge.org.uk/public-health-textbook/ research-methods/1a-epidemiology/electronic-bibliographies

5. Cochrane Database of Systematic Reviews Included in MEDLINE. NLM Tech Bull 2002;(324):e6. http://www.nlm. nih.gov/pubs/techbull/jf02/jf02_cochrane.html

6. EBSCO, CINAHL Complete. Nursing Resources from EBSCO Health; 2014. http://www.ebscohost.com/nursing/ products/cinahl-databases/cinahl-complete

7. Wikipedia. CINAHL; 2013. http://en.wikipedia.org/wiki/ CINAHL

8. Elsevier Life Science Solutions. Scopus; 2014. http://www. elsevier.com/online-tools/scopus

9. NIH, U.S. National Library of Medicine. Number of Titles Currently Indexed for Index Medicus and MEDLINE on PubMed; 2014. http://www.nlm.nih.gov/bsd/num_titles.html

10. Sarli CC, Dubinsky EK, Holmes KL. Beyond citation analysis: a model for assessment of research impact. J Med Libr Assoc 2010;98(1):17-23. CrossRef

11. Küçükdurmaz F, Aytekin MN, Tuncay I, Şen C. Sağlıkla ilgili Türkçe web sitelerindeki bilgilerin kalitesi üzerine bir pilot çalışma: menisküs yırtığı. Nobel Med 2013;9(2):114-7.

12. Dapra D. Indexing Repository Content in Google Scholar. Digit Commons Webinars 2012. http://digitalcommons. bepress.com/webinars/24/

13. Shariff SZ, Bejaimal SA, Sontrop JM, lansavichus AV, Haynes RB, Weir MA, Garg AX. Retrieving clinical evidence: a comparison of PubMed and Google Scholar for quick clinical searches. J Med Internet Res 2013;15(8):e164. CrossRef
14. Nourbakhsh E, Nugent R, Wang H, Cevik C, Nugent $K$. Medical literature searches: a comparison of PubMed and Google Scholar. Health Info Libr J 2012;29(3):214-22. CrossRef

15. Gelfand J. Grey Literature: Plausible Applications for Distance Education Practices. In: GL'99 Conference Proceedings: Fourth International Conference on Grey Literature. Washington D.C. - Amsterdam: GreyNet; 2000.

16. Higgins JPT, Green S, editors. Cochrane Handbook for Systematic Reviews of Interventions, Version 5.1.0 [updated March 2011] The Cochrane Collaboration; 2011. http:// www.cochrane-handbook.org

17. Mallett S, Hopewell S, Clarke M. Grey literature in systematic reviews: The first 1000 Cochrane systematic reviews. Fourth Symposium on Systematic Reviews: Pushing the Boundaries. Oxford (UK): 2002.

18. Conn VS, Valentine JC, Cooper HM, Rantz MJ. Grey literature in meta-analyses. Nurs Res 2003;52(4):256-61.

19. Dickersin K, Min YI, Meinert CL. Factors influencing publication of research results. Follow-up of applications submitted to two institutional review boards. JAMA 1992;267(3):374-8.

20. EasterbrookPJ, BerlinJA, Gopalan R, Matthews DR. Publication bias in clinical research. Lancet 1991;337(8746):867-72.

21. Rosenbaum WL, Sterling TD, Weinkam JJ. Correcting standardized rate ratios for imprecise classification of a polychotomous exposure variable with limited data. Am J Epidemiol 1995;142(4):442-5.

22. Begg CB, Berlin JA. Publication bias and dissemination of clinical research. J Natl Cancer Inst 1989;81(2):107-15.

23. Küçükdurmaz F. Akılcı Veri Tabanı Erişimi. 22. Ulusal Türk Ortopedi ve Travmatoloji Kongresi, 31 Ekim - 05 Kasım 2011, Belek, Antalya.

24. Küçükdurmaz F, Sukeik M. Literature Search Techniques in Orthopaedics and Traumatology. EFORT 2014, June 4-6, 2014, London, UK. 